\title{
MAPEAMENTO DAS EMPRESAS DO SETOR AGRONEGÓCIO DO MUNICÍPIO DE TUPÃ/SP: UM ESTUDO SOBRE O CONTEXTO DA INSERÇÃO DA EDUCAÇÃO E GESTÃO AMBIENTAL
}

\author{
Matheus Prevelato Gantus ${ }^{1}$ \\ Cristina Toyoko Hashimoto ${ }^{2}$
}

Angélica Gois Morales ${ }^{3}$

\begin{abstract}
RESUMO: A educação ambiental, aos poucos, adentra diversos setores tanto formais como não-formais e, por sua dimensão socioambiental sistêmica e complexa, vem ganhando cada vez mais atenção, principalmente num mercado competitivo e globalizado, aparecendo consideravelmente nas negociações dos dias atuais. No ambiente empresarial, torna-se importante a educação no processo de gestão ambiental por ser vista como um dos processos do desenvolvimento, responsável pela mudança de mentalidades e atitudes, bem como pela formação de novas identidades sociais. Frente a importância da educação e gestão ambiental, esse estudo teve como objetivo diagnosticar as empresas do setor agronegócio do município de Tupã, Estado de São Paulo, a fim de verificar a presença da educação e a gestão ambiental. Dentre essas empresas, delimitou-se 22, sendo que nenhuma possui a certificação da norma ISO 14001 e a inserção da educação ambiental ainda são ações pontuais, sem articulação, o que evidencia o esvaziamento da educação ambiental no ambiente empresarial.
\end{abstract}

Palavras-Chave: Educação ambiental. Gestão ambiental. Empresas do setor agronegócio.

\footnotetext{
${ }^{1}$ Discente, bolsista do Programa Institucional de Bolsas de Iniciação Científica (PIBIC), Univ. Estadual Paulista "Júlio de Mesquita Filho" (UNESP), Câmpus Experimental de Tupã.

matheusao_tupa@hotmail.com

${ }^{2}$ Discente, Univ. Estadual Paulista "Júlio de Mesquita Filho" (UNESP), Câmpus Experimental de Tupã. toyokohashimoto@gmail.com

${ }^{3}$ Doutora em Meio Ambiente e Desenvolvimento (UFPR), Univ. Estadual Paulista "Júlio de Mesquita Filho" (UNESP), Câmpus Experimental de Tupã. Docente do curso de Administração.

angélica@tupa.unesp.br
} 


\section{INTRODUÇÃO}

O tema ambiental não é um tema necessariamente novo, há décadas ele já vem entrando em pautas nos diversos encontros internacionais a cerca da crescente preocupação atual com o meio ambiente, no entanto, por ser um tema emergente, nos últimos trinta anos ele vem passando a ser discutido com uma ênfase consideravelmente maior do que em outras décadas mais distantes (BARBIERI, 2004).

Diante dessa degradação, a gestão ambiental tem sido muito reforçada nas últimas décadas, emergindo da própria necessidade do ser humano organizar melhor suas diversas formas de se relacionar com o ambiente. Nesse sentido, frente a uma sociedade moderna de risco ${ }^{4}$, a gestão e a educação ambiental tende a ser uma das mediadoras na (re) construção das relações de reapropriação do mundo, o que implica ações coletivas acompanhadas de discurso político em torno das questões socioambientais e de uma racionalidade produtiva alternativa (MORALES, 2009).

O processo de gestão ambiental possibilita às organizações exercerem sua responsabilidade socioambiental nos negócios e, por isso, é considerado como uma das prioridades de qualquer empresa que ainda pretende manter-se competitiva no contexto atual. E, nesse engajamento, diversas organizações iniciou um processo de gestão ambiental por meio das oportunidades decorrentes da certificação ISO 14000 , que é uma série de normas de Gestão Ambiental, que impõe regras de conservação ambiental e gerenciamento, como a norma brasileira NBR 14001:2004, que versa sobre a implantação de um Sistema de Gestão Ambiental (SGA).

Para tanto, para essa implementação, torna-se importante à educação no processo de gestão ambiental por ser vista como um dos processos do

\footnotetext{
${ }^{4}$ Remete-se ao conceito de risco de Ulrich Beck, como consequência da sociedade moderna, tendo como pano de fundo o industrialismo e a tecnologia. Como ele próprio aborda, "este conceito designa uma fase no desenvolvimento da sociedade moderna, em que os riscos sociais, políticos, econômicos e individuais tendem cada vez mais a escapar das instituições para o controle e a proteção da sociedade industrial” (BECK, 1997,p.15). Dessa forma, o autor afirma que os riscos são universais, sejam eles naturais, humanos como tecnológicos, podendo estar relacionados tanto a perigos visíveis (como catástrofes, mudança climática) quanto a invisíveis e incertos (aqueles que estão por vir e que não tem como prevenir).
} 
desenvolvimento, responsável pelas estruturas das políticas de conhecimento, pela mudança de mentalidades e atitudes, bem como pela formação de novas identidades sociais (MORALES, 2009).

Realmente, a educação ambiental vem se destacando também entre os assuntos, como uma questão fundamental para toda a sociedade. (ALBAGLI,1995; GUIMARÃES, 1995; BRAGA et al., 2002; JACOBI, 2003). Assim, a educação ambiental, aos poucos, adentra diversos setores tanto formais como não-formais e, por sua dimensão socioambiental sistêmica e complexa, vem ganhando cada vez mais atenção, principalmente num mercado competitivo e globalizado, aparecendo consideravelmente nas negociações dos dias atuais.

Portanto, para delinear os caminhos que as empresas vês realizando dentro da gestão e educação ambiental e, também, por essa pesquisa estar direcionada no extremo oeste paulista, no qual as atividades do setor agronegócio são predominantes, a problematização central é: As empresas do setor agronegócio do município de Tupã (SP) possuem educação ambiental e o processo de Sistema de Gestão Ambiental?

Frente ao exposto, esse trabalho teve como objetivo diagnosticar as empresas do setor agronegócio do município de Tupã, Estado de São Paulo, a fim de verificar a presença da educação e da gestão ambiental.

\section{REVISÃO BIBLIOGRÁFICA}

Conforme Barbieri (2007), a terminologia gestão ambiental refere-se a um leque de variedades com quaisquer iniciativas destinadas aos problemas ambientais. Gestão Ambiental, segundo Ribeiro (2000), é administrar uma bacia hidrográfica, uma unidade de conservação, um processo industrial, um bairro, uma secretaria municipal de meio ambiente, uma empresa, ou ainda, uma cidade, e tomá-los como ecossistemas, diminuindo os impactos negativos, a fim de evitar uma degradação, manter suas características desejáveis e aperfeiçoar aquelas que carecem de melhorias. Leff (2001) ainda aborda que os princípios de gestão ambiental propõem uma necessária transformação que tenha a convergência dos interesses em conflito e dos objetivos comuns dos diferentes grupos e classes sociais em torno do desenvolvimento. 


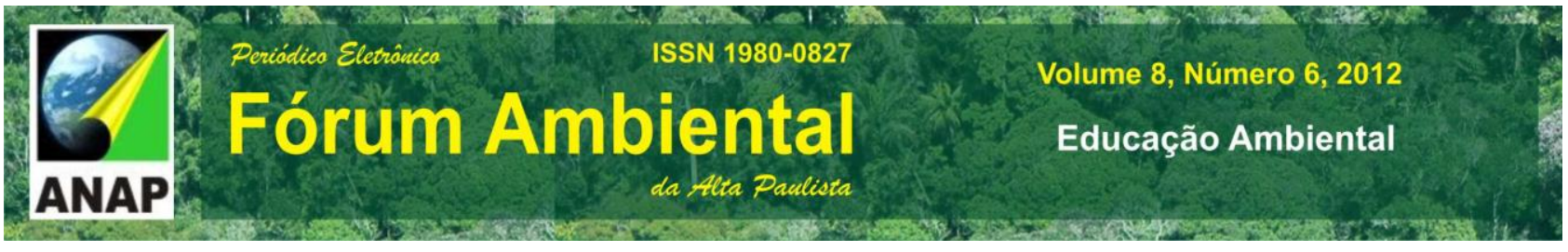

Para Rohrich e Cunha (2004), gestão ambiental deve se a uma união de elementos que se constituem de políticas e práticas administrativas e operacionais relevando a saúde dos seres humanos e, também, a segurança das pessoas caracterizando, assim, a proteção do meio ambiente por meio da "eliminação ou diminuição dos impactos ambientais decorridos de planejamento, implantação, operação, ampliação, realocação" (ROHRICH e CUNHA, 2004), ou desativação de processos ou atividades, que insere todas as fases da vida do produto.

Da prática da gestão ambiental originaram-se diversas preocupações em vários setores da sociedade, principalmente nos setores do agronegócio e empresarial, em que a relação entre recursos naturais e econômicos estão fortemente ligados (BARBIERI, 2007).

Segundo Lima Filho (2006), a gestão ambiental no agronegócio visa o respeito ao ambiente natural, a segurança do alimento e o bem estar animal. No setor empresarial, as práticas ambientais são influenciadas por pressões de três forças que interagem mutuamente: a sociedade, o governo e o mercado. No agronegócio, a prática da gestão ambiental abrange sobre todos os setores da cadeia produtiva, desde a produção de insumos, produção rural até 0 consumidor final, e com o desenvolvimento tecnológico, os agentes das cadeias agroindustriais têm buscado maneiras de reduzir os impactos destrutivos no meio ambiente sem necessariamente reduzir a produtividade (SCHENINI, PEREIRA e GUINDANI, 2006).

A gestão ambiental empresarial teve um crescimento significativo devido, principalmente às pressões por parte da sociedade e de medidas aplicadas pelo governo. Talvez, caso não houvesse tais pressões, não haveria o aumento do envolvimento empresarial com as questões ambientais. Com a frequência das aprovações de leis ambientais e o aumento de ONGs envolvidas, as questões ambientais passaram a ter importância na competitividade dos países e de suas empresas (BARBIERI, 2007).

Com todas essas exigências ao redor do setor organizacional, cada vez mais as empresas estão preocupadas em tornarem-se sistemas mais próximos de um caminho sustentável possível. De tal modo, as organizações necessitam realizar um processo de transformação em sua cultura, administrando essa mudança para uma cultura 
empresarial com preocupação e consciência ecológica (CAPRA e CALLENBACH, 1993). Frente a isso, o Sistema de Gestão Ambiental, implantada pela norma ISO 14001, representam para as empresas “(...) uma alternativa para a adoção de práticas ambientalmente corretas, as quais contribuem, também, para o incremento da qualidade de seus produtos, serviços e processos" (PEDRINI, 2008, p. 26).

Para tal, as empresas começam, mesmo com passos lentos, a reconhecer a necessidade de trabalhar e promover a educação ambiental, principalmente, entre seus funcionários. Essa conduta é mais perceptível, quando há o interesse da empresa em implantar um SGA (PEDRINI, 2008).

A educação ambiental, legalmente, deve estar envolvendo todos os setores da sociedade, e, nesse encaminhamento, o gerenciamento ambiental convoca as empresas a incorporarem a dimensão socioambiental nas suas atividades produtivas e os órgãos públicos, por conseguinte, a buscarem por meio de um processo de educação ambiental, uma participação ativa na implementação de seus programas que contribuam para uma possível sustentabilidade e melhoria na qualidade ambiental.

O tema educacional integra a verdadeira educação econômica pelo qual não se trata apenas da gestão do meio ambiente, pois, antes disso, tem-se que gerir a gestão das próprias condutas individuais quanto às coletivas respeitando os recursos disponíveis que são retirados desta natureza que temos ao nosso redor (SAUVÉ, 2005). Sendo assim, a concepção de educação ambiental torna-se mais complexa, já que as dimensões sociais, culturais, políticas, econômicas e ecológicas são incorporadas "com enfoque em conhecer e compreender as realidades e as problemáticas ambientais sob a visão da totalidade" (MORALES, 2009, p.50).

\section{METODOLOGIA}

A metodologia utilizada na pesquisa foi de recorte qualitativo a partir de um estudo descritivo. Essa abordagem se deu pelos interesses centrais focados no significado em função dos resultados conferidos as pessoas responsáveis estimulando dessa forma o entendimento e compreensão das respostas descritas obtidas através 
dos dados levantados a fim de não necessitar estar medidos ou quantificados (TRIVIÑOS, 1987).

Como sujeitos da pesquisa, foram utilizadas empresas do setor do agronegócio da cidade de Tupã. A cidade de Tupã localiza-se na região da Nova Alta Paulista, que abrange cerca de 30 municípios, os quais abrangeram suas fundações alavancadas entre as décadas de 1930 e 1960, assim acabou-se verificando que foi às últimas localidades do interior do Estado de São Paulo a serem povoadas (MOCHIUTI et al., 2011). Por esse motivo deve-se mensurar que esta se caracteriza como uma região desprovida de muitos recursos financeiros, povoada por famílias de essências ruralistas, assumindo como maior parte da renda familiar, a agricultura. E, conforme foi ocorrendo às crises de algodão, café, amendoim dentre outras culturas, houve fortes transformações nessa área, o que acarreta em grandes consequências até os dias atuais, como uma grande influencia nos produtores rurais, que são fortes na economia regional, assim como na aquisição de estratégias produtivas diferenciadas como na inserção de diferentes comércios (MOCHIUTI et al., 2011).

Em divisão territorial datada de 1VI-1995, o município de Tupã é constituído de 4 Distritos, Tupã, Parnaso, Universo e Varpa (IBGE, 2009).

Figura 1- Público alvo: Tupã - São Paulo

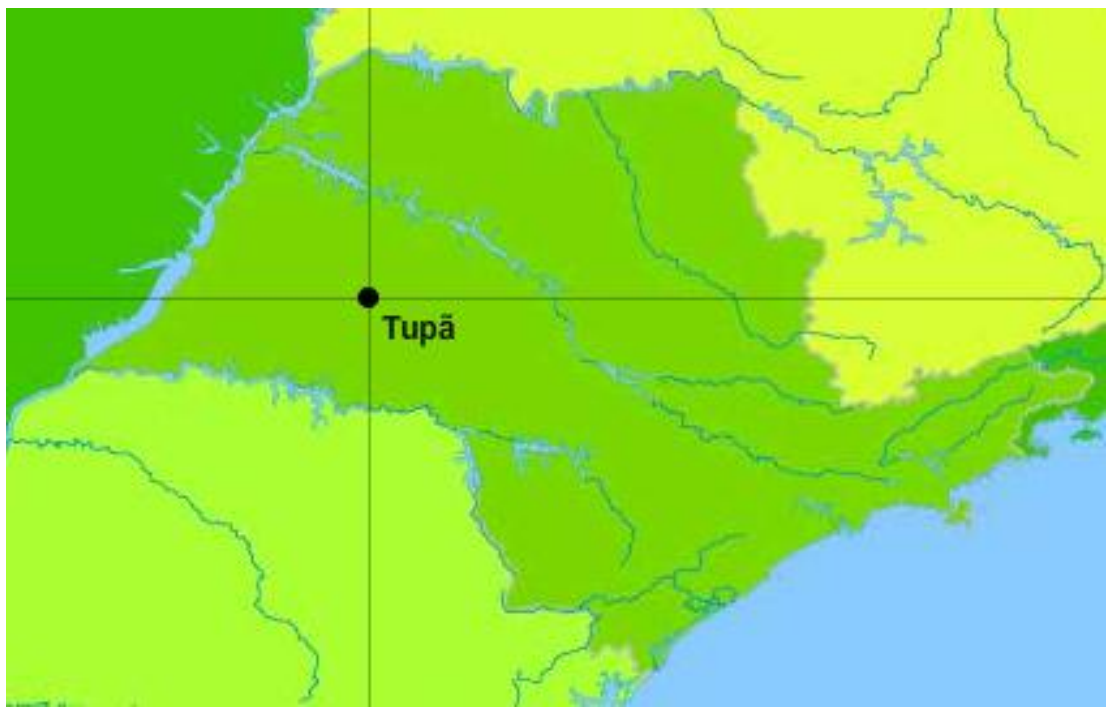

Fonte: IBGE, 2009 
Portanto, dentro do contexto do munícipio de Tupã, por meio de um mapeamento inicial, buscou-se, primeiramente, ter acesso a lista das empresas que foram cedidas pela prefeitura. A partir dessa lista, realizou-se um recorte das empresas que estavam diretamente ligadas ao setor do agronegócio, dando um total de 22 empresas.

$\mathrm{Na}$ próxima etapa, foi realizado o envio de questionários semi-estruturados (questões abertas e fechadas) às empresas com o objetivo de verificar se as mesmas possuem a inserção de educação ambiental e de gestão ambiental, bem como se possuem a implantação do SGA.

No entanto, com o pouco retorno das empresas, foi necessário realizar a saída de campo. Segundo Teixeira (2001), de acordo com o levantamento dos dados da pesquisa dos organismos que não se obteve respostas, torna-se importante uma pesquisa de campo. Essa pesquisa ocorreu entre dois meses, Foram realizados os contatos pessoalmente com os responsáveis pela área ambiental de suas organizações ou os próprios proprietários assim, com auxílio de uma cooperação dos mesmos em uma maior facilidade na condução do preenchimento do roteiro dos questionários.

As variáveis requisitadas foram: atividades desenvolvidas na área de gestão e educação ambiental, certificações ambientais, ramo de atividade. Por meio das informações coletadas obtiveram-se as análises de forma quanti-qualitativa, no qual os dados puderam ser traduzidos em números e em contextos, por meio de uma visão sistêmica, verificando o todo por meio de interpretações dos dados, o que implica na possibilidade de refletir, pensar e conhecer a realidade, para que possa possam chegar aos indicadores de ações de melhoria no processo da gestão ambiental, com enfoque na educação ambiental.

\section{RESULTADOS E DISCUSSÕES}

De acordo com Pinto (2009, p. 438), "o setor do agronegócio pode ser subdividido em mais duas categorias: a de fornecedores de insumos agrícolas, máquinas e equipamentos e a de processamento industrial, de distribuição e serviços". Atualmente, as atividades econômicas 
que mais cresceram nos últimos anos, o agronegócio encontra-se em destaque nacional, pois responde por um em cada três reais gerados no Brasil. Além disso, é responsável por $42 \%$ das exportações totais do país e 33\% do Produto Interno Bruto (PIB), de acordo com dados de 2004 do Ministério da Agricultura, Pecuária e Abastecimento. (BRASIL, 2011).

O agronegócio, nesse intenso crescimento vem acompanhado da preocupação socioambiental, tornando a gestão e a educação ambiental, fatores importantes que merecem atenção das empresas.

Em Tupã, por possuir economia voltada predominantemente, às atividades agropecuárias, como culturas de algodão, amendoim, entre outros, já foi destaque na região por ter se adaptado á agropecuária (MOCHIUTI, 2001). Dentre as 22 empresas mapeadas que estão ligadas ao setor do agronegócio, encontram-se no ramo de artefatos de madeira, agro metalúrgica, frigorífico, indústria de alimentos, indústria de fertilizantes, indústria de óleos vegetais, entre outros, que se encontram na cadeia do agronegócio.

No entanto, das 22 empresas, nenhuma possui a implantação do SGA. De todas as empresas mapeadas, apenas três empresas, alegaram estar desenvolvendo medidas para a implementação da norma ISO 14001, em suas unidades de negócio.

Notou-se também que a maioria dos proprietários das empresas pesquisadas possui um desentendimento do que realmente seja a norma ISO 14000 e a ISO 14001 que refere-se ao Sistema de Gestão Ambiental e quais normas que podem ser aplicadas em suas organizações. Porém, mesmo sem o SGA, há 13 (59\%) empresas que desenvolvem atividades de educação ambiental, como incentivo ao plantio de árvores, palestras educativas, coleta seletiva dos resíduos sólidos, aproveitamento do óleo de fritura, incentivo aos agricultores para o não uso de agrotóxicos. Tais atividades, consideradas como práticas ambientais, são condutas que contribuem para o ambiente, mas exige uma permanência da conduta, e não leva a reflexão, muitas vezes. A educação ambiental é um processo, e, muitas vezes, acaba sendo encarada como ações pontuais, levando muitas vezes apenas a um treinamento, tendo como base uma visão ainda instrumental (BRUGGER, 1994)

Nota-se que os empresários que possuem práticas na área ambiental não possuem uma preocupação em se enquadrar nas normas do SGA, pois deve-se ao fato de presumirem que como já possuem alguma atividades, essa é a contribuição de cada empreendimento para o meio ambiente. Percebe-se também que não há uma 
preocupação grande com aqueles empresários que não exercem nenhuma atividade na área referida.

Para uma das empresas pesquisadas, no ramo de distribuição de energia elétrica, é adotado um programa de eficiência energética, no qual é desenvolvido vários programas relativos ao uso racional de energia elétrica por meio de ações educativas.

Sabe-se que é recente a preocupação com ações educativas, principalmente, da educação ambiental nas empresas e, aquelas que acabam tendo tal conduta, tem esse encaminhamento devido ao cumprimento de exigências para licenciamento, selos de certificação, imagem da empresa, entre outros (PEDRINI, 2008).

\section{CONCLUSÃO}

Conclui-se que a partir das variáveis apresentadas nesse mapeamento inicial, as empresas privadas da cidade em estudo, ainda tem uma cultura organizacional limitada diante das questões ambientais que envolvem o microambiente onde estão inseridas.

Torna-se importante a inserção da educação ambiental no ambiente empresarial, pois mesmo que inicie por pequenas ações, é possível que tornem-se integradoras e significativas, deixando-se de ser apenas ações pontuais, decorrentes de um desastre ou apenas como uma data comemorativa.

\section{REFERÊNCIAS}

ALBAGLI, S. Novos espaços de regulação na era da informação e do conhecimento. In: LASTRES, H. M. M.; LABAGLI, S. Informação e globalização na era do conhecimento. Rio de Janeiro: Campus, 1995. p.290-313.

BARBIERI, J. C. Gestão ambiental empresarial. São Paulo: Saraiva, 2004.

BECK, U. Modernização reflexiva: política, tradição e estética na ordem social moderna. São Paulo: UNESP, 1997

BRAGA, B. et al. Introdução à engenharia ambiental. São Paulo: Prentice Hall, 2002.

BRASIL. Ministério da Agricultura, Pecuária e Abastecimento. Disponível em: <http://www. agricultura.gov.br/>. Acesso em: 15 jun. 2011 
BRÜGGER, P. Educação ou adestramento ambiental? Florianópolis (SC): Letras contemporâneas, 1994.

CALLENBACH, E., CAPRA, F. Gerenciamento ecológico: guia do Instituto Elmwood de Auditoria Ecológica e Negócios Sustentáveis. São Paulo: Cultrix, 1993.

GUIMARÃES, M. A dimensão ambiental na educação. Campinas: Papirus, 1995.

IBGE. Histórico. 2009. Disponível em: <http://www.ibge.gov.br/cidadesat/painel/ painel.php?codmun=355500\#> Acesso em: 22 out. 2012.

JACOBI, P. Educação ambiental, cidadania e sustentabilidade. Cadernos de Pesquisa, São Paulo, n. 118, p.189-205, mar. 2003.

LEFF, E. Saber ambiental: sustentabilidade, racionalidade, complexidade, poder. Rio de Janeiro: Vozes, 2001.

LIMA FILHO, D. O. Ambiente natural e desenvolvimento: as cadeias agroindustriais estão fazendo o dever de casa. In: SCHENINI, P.C. PEREIRA, M.F. GUINDANI, R.A. Gestão Ambiental no Agronegócio. Florianópolis: Papa-Livro, 2006.

MOCHIUTI, J. C. et al. Estudo sobre a composição da renda e a lógica de funcionamento dos sistemas de produção agropecuários em tupã-SP. Omnia Exatas, v.4, n.2, 77-86, Julho/Dezembro de 2011.

MORALES, A. G. O profissional educador ambiental: reflexões, possibilidades e constatações. Ponta Grossa:UEPG, 2009.

PEDRINI, A. de G. Educação Ambiental empresarial no Brasil. São Carlos: Rima, 2008.

PINTO, F.R. et al. A percepção dos empresários do setor de agronegócio sobre as práticas de responsabilidade social. Revista Econômica do Nordeste, v.4, n.3, jul./set.2009. p. 437-452.

RIBEIRO, M. A. Ecologizar: pensando o ambiente humano. Belo Horizonte: Rona, 2000.

ROHRICH, S. S.; CUNHA, J. C. A proposição de uma taxonomia para a análise da gestão ambiental no Brasil. Revista de Administração Contemporânea, v. 8, n. 4, p. 86-95, 2004.

SAUVÉ. L.: Educação Ambiental: possibilidades e limitações. São Paulo. Université Du Québec à Montréal, v. 31, n. 2, p. 317-322, 2005.

SCHENINI, P.C. PEREIRA, M.F. GUINDANI, R.A. Gestão Ambiental no Agronegócio. Florianópolis: Papa-Livro, 2006.

TEIXEIRA, J. J.V. A prescrição medicamentosa sob a ótica do paciente idoso. São Paulo: FSP/USP. 2001. 208-210 p. Dissertação de mestrado apresentada à Faculdade de Saúde Pública da Universidade de São Paulo.

TRIVINOS, A. N. S. Introdução a pesquisa em Ciências Sociais: a pesquisa qualitativa em educação. São Paulo: Atlas, 1987. 175p. p.91-115. 